\title{
Randomised pilot study of dose escalation using conformal radiotherapy in prostate cancer: long-term follow-up
}

\author{
A Creak ${ }^{1}$, E Hall ${ }^{2}$, A Horwich ${ }^{1}$, R Eeles ${ }^{1}$, V Khoo ${ }^{1}$, R Huddart ${ }^{1}$, C Parker ${ }^{1}$, C Griffin ${ }^{2}$, M Bidmead ${ }^{3}$, J Warrington ${ }^{3}$ \\ and D Dearnaley ${ }^{*} 1$ \\ ${ }^{1}$ Academic Urology Unit, The Institute of Cancer Research and The Royal Marsden NHS Foundation Trust, Sutton and London, UK; \\ ${ }^{2}$ Clinical Trials and Statistics Unit (ICR-CTSU), The Institute of Cancer Research, London, UK and ${ }^{3}$ Joint Department of Physics, \\ Royal Marsden Hospital Trust and The Institute of Cancer Research, Sutton and London, UK
}

Background: Radical three-dimensional conformal radiotherapy (CFRT) with initial androgen suppression (AS) is a standard management for localised prostate cancer (PC). This pilot study evaluated the role of dose escalation and appropriate target volume margin. Here, we report long-term follow-up.

Methods: Eligible patients had T1b-T3b NO MO PC. After neoadjuvant AS, they were randomised to CFRT, giving (a) 64 Gy with either a 1.0- or 1.5-cm margin and (b) $\pm 10 \mathrm{~Gy}$ boost to the prostate alone.

\begin{abstract}
Results: One hundred and twenty-six men were randomised and treated. Median follow-up was 13.7 years. The median age was 66.6 years at randomisation. Median presenting prostate-specific antigen (PSA) was $14 \mathrm{ng} \mathrm{m}^{-1}$. Sixty-four out of 126 patients developed PSA failure. Forty-nine out of 126 patients restarted AS, 34 out of 126 developed metastases and 28 out of 126 developed castrate-resistant prostate cancer (CRPC). Fifty-one out of 126 patients died; 19 out of 51 died of PC. Median overall survival (OS) was 14.4 years. Although escalated dose results were favourable, no statistically significant differences were seen between the randomised groups; PSA control (hazard ratio (HR): 0.77 (95\% confidence interval (Cl): 0.47-1.26)), development of CRPC (HR: 0.81 (95\% Cl: 0.40-1.65)), PC-specific survival (HR: 0.59 (95\% Cl:0.23-1.49)) and OS (HR: 0.81 (95\% Cl: 0.47-1.40)). There was no evidence of a difference in PSA control according to margin size (HR: 1.01 (95\% Cl: 0.61-1.66)).
\end{abstract}

Interpretation: Long-term follow-up of this small pilot study is compatible with a benefit from dose escalation, but confirmation from larger trials is required. There was no obvious detriment using the smaller radiotherapy margin.

Prostate cancer (PC) is the commonest malignancy in men. In 2009, there were 40841 new cases of PC diagnosed in the United Kingdom (CRUK, 2009). Substantial increases in incidence have been reported in recent years, reflecting the increasing use of prostate-specific antigen (PSA) screening.

Radical conformal external beam radiotherapy, in conjunction with initial androgen suppression (AS), is now a standard form of management of localised PC (NICE, 2008). This trial evaluated the role of dose escalation and the appropriate target volume margin after short-course AS. It was the 'pilot study' and provided initial safety and feasibility information for the national MRC RT01 trial and closed to recruitment in January 1998. It is the only reported randomised study to specifically look at appropriate margin size in localised PC radiotherapy treated with initial AS. Initial results were reported in 2005 after a median follow-up of 6.2 years (Dearnaley et al, 2005) and this was followed by the 5-year follow-up for the RT01 trial in 2007 (Dearnaley et al, 2007), which led to doseescalated conformal radiotherapy (CFRT) being recommended as a 'standard of care' for localised PC in the United Kingdom (NICE, 2008). We now report long-term follow-up of the pilot study.

*Correspondence: Professor D Dearnaley; E-mail: David.Dearnaley@icr.ac.uk

Received 1 March 2013; revised 10 June 2013; accepted 22 June 2013; published online 23 July 2013

(c) 2013 Cancer Research UK. All rights reserved 0007-0920/13 


\section{MATERIALS AND METHODS}

Trial design and methodology have been previously described (Dearnaley et al, 2005). A $2 \times 2$ factorial design was used to deliver a radiation dose of $64 \mathrm{~Gy}$ with (a) either a 1.0- or 1.5- $\mathrm{cm}$ margin around the target volume and (b) either with or without a 10-Gy boost to the prostate alone (74 Gy or 64 Gy groups). The study was approved by the RMT and ICR Clinical Research and Ethics Committees (EC No. 1104). All men participating in the trial gave written informed consent.

Eligibility. Eligible patients had histologically proven T1b-T3b N0 M0 PC. There was no limit on pre-treatment PSA levels, and any histological grade was accepted.

Treatment. All patients were treated with initial AS using monthly luteinising hormone analogue (LHRHa) depot injections given for 3-6 months before and continued during radiotherapy. Short-course anti-androgen therapy was given using cyproterone acetate to prevent testosterone 'flare'. All radiotherapy treatments used three-dimensional (3D) conformal techniques. The radiotherapy target volume included the prostate and all or part of the seminal vesicles (SVs), depending on the risk of SV invasion (Roach III, 1993). Patients were randomised to have either a $1-$ or $1.5-\mathrm{cm}$ uniform margin added to this target volume to create the planning target volume (PTV 1). The rationale was to mimic the change between pre- and post-hormone treatment prostate volumes as we had previously shown on average a $0.5-\mathrm{cm}$ reduction in prostate radius with neoadjuvant AS (Dearnaley, 2000). Patients randomised to the escalated dose group ( $74 \mathrm{~Gy}$ ) had a phase II boost to the prostate alone, with no margin added (PTV 2).

All patients were treated in phase I to a dose of $64 \mathrm{~Gy}$ in 32 fractions over $6 \frac{1}{2}$ weeks using a standard three-field plan (anterior and left/right lateral or posterior oblique fields; Khoo et al, 2000). Those in the escalated dose group went on to receive a phase II treatment, $10 \mathrm{~Gy}$ in five fractions over 1 week, using a six-field arrangement (left and right, anterior/posterior oblique and lateral fields; Pickett et al, 1994). All doses were prescribed to the isocentre. Beam shaping was with multileaf collimators or customised-shaped blocks, and treatment was delivered with 6-10 MV photons as previously described (Dearnaley et al, 2005). No dose constraints for normal tissues were specified. Verification was with daily and then weekly port films/images.

Salvage hormonal therapy was restarted if there was evidence of clinical or radiological progression, a PSA doubling time of $\leqslant 6$ months, or for patient preference.

Patient follow-up. Tumour control was monitored by serial (annual from 5 years after treatment) PSA testing and clinical examination, with imaging investigations performed where appropriate.

Given the limitations of the assays used during the earlier years of the study, we defined biochemical failure as either two consecutive rises in PSA $\geqslant 2 \mathrm{ng} \mathrm{ml}^{-1}$ or the recommencement of androgen deprivation. The date of PSA failure was taken as the date of the first PSA value $\geqslant 2 \mathrm{ng} \mathrm{ml}^{-1}$.

Follow-up information was updated from trial proformas and supplemented by information from the hospital electronic record system. For any patient who was lost to follow-up (not seen since March 2009), information was obtained by contacting GPs or by direct patient contact. Any unknown cause of death was clarified by obtaining death certificates. Data was collected until November 2010 .

Disease-related end points. The primary end point was PSA control. Secondary end points included recommencement of AS, development of metastases, development of castration-resistant prostate cancer (CRPC; defined as time to starting second-line hormonal therapy in a patient who had progressed on first-line salvage hormonal therapy, that is, LHRH analogue or bicalutamide monotherapy), PC-related death and overall survival (OS).

Disease recurrence and the cause of death were determined (AC, DD) by review of all medical data available; review was performed before any analysis and without reference to treatment allocation. Patients dying with CRPC and a PSA $>4 \mathrm{ng} \mathrm{ml}^{-1}$, and patients recorded as dying of PC on their death certificate, where this was compatible with the available detailed clinical follow-up information, were categorised as PC-related deaths (with patients censored at date last follow-up or death from other cause). Sensitivity analyses including these events as PC-related deaths gave results consistent with the primary analysis.

Statistical analysis methods. All analyses are by intention to treat and include 126 out of 127 patients randomised. One patient withdrew before any treatment was given and was excluded from the analysis. Median follow-up is calculated by the reverse KaplanMeier method. Each survival end point is measured from the date of randomisation and is analysed with the same methodology. The principal analysis is based on a log-rank comparison, stratified by margin for dose comparison and vice versa. Kaplan-Meier survival curves are presented with 10-year fixed term survival estimates and $95 \%$ confidence intervals (CIs). Median time to event is reported where this has been reached.

Hazard ratios (HRs) from a Cox model (adjusting for margin in the dose comparison and vice versa) are calculated (HRs $<1$ in favour of $74 \mathrm{~Gy}$ and in favour of $1.0 \mathrm{~cm}$ margin) and presented along with 95\% CIs. The proportional hazards assumption of the Cox model, which was tested using Schoenfeld residuals, held for each end point. The presence of an interaction between dose and margin was tested for each end point (all non-significant) but the test had low power because of the small size of the study. Interaction terms are not included in the data presented. Analyses were conducted in STATA v11 (StataCorp, College Station, TX, USA).

\section{RESULTS}

One hundred and twenty-six men were randomised and treated at the Royal Marsden NHS Trust between July 1995 and December 1997 (Figure 1). The baseline characteristics were evenly balanced between the groups (Dearnaley et al, 2005).

The median follow-up was 13.7 years. Median age was 66.6 years (IQR: 62.5-71.8) at randomisation and 78.5 years (IQR: 74.183.7) at last follow-up (in 75 patients alive). Median presenting PSA was $14 \mathrm{ng} \mathrm{ml}^{-1}$ (range 1-142). Tumour staging was T1 in $21 \%$ (26 patients), T2 in 50\% (63 patients) and T3 in 29\% (37 patients), respectively. Well, moderately and poorly differentiated pathology was reported in 18\% (22 patients), $72 \%$ (91 patients) and $10 \%$ (13 patients), respectively. In all, 20\% (25 patients), 27\% (34 patients) and 53\% (67 patients) had low-, intermediate-, and highrisk $\mathrm{PC}$, respectively. One patient in the $74 \mathrm{~Gy} / 1.5 \mathrm{~cm}$ margin group was lost to follow-up (through emigration) 1.8 years after randomisation.

None of the results presented reach statistical significance owing to the small size of the trial.

There have been 64 out of 126 (50.8\%) patients who have developed PSA failure. Forty-nine out of 126 (38.9\%) patients have restarted hormonal therapy. Thirty-four out of 126 men (27.0\%) have developed metastatic disease ( 11 bone, 9 nodal, 6 nodal and bone, 3 lung, 2 bone and liver, 1 liver and 2 unknown (died of PC)) and 31 out of $126(24.6 \%)$ have developed CRPC. A total of 51 out of $126(40.5 \%)$ patients have died; 19 out of 51 (37.3\%) died of PC. Of the 64 men with PSA failure, $11(17.2 \%)$ remain on an 
observation policy without further treatment. Median OS for all patients was 14.4 years.

Dose randomisation. Thirty-four men developed PSA failure in the 64-Gy group compared with 30 men in the 74-Gy group (HR: $0.77,95 \%$ CI: $0.47-1.26$ ). Median time to PSA failure was 7.7 years in the 64-Gy group and 10.0 years in the $74-G y$ group. The 10 -year actuarial control rates are $45.3 \%$ and $49.3 \%$ in the $64-G y$ and 74-Gy groups, respectively (Table 1, Figure 2A).

Hazard ratios for the other end points (time to restart of hormones, time to metastatic disease, time to CRPC, PC-specific survival and OS) were in favour of the 74-Gy group, although statistical significance was not met (Table 1, Figure $2 \mathrm{C}-\mathrm{G}$ ). In particular, we recorded 12 PC-related deaths in the 64-Gy group and 7 in the 74-Gy group. In the low-, intermediate- and high-risk disease groups, 2 out of 25 (8.0\%), 1 out of 34 (2.9\%) and 16 out of 67 (23.9\%) men, respectively, died of PC. In patients with initial PSA levels $<10,10-20$ and $>20 \mathrm{ng} \mathrm{ml}^{-1}$, PC-related deaths were recorded for 3 out of 42 (7.1\%), 2 out of 35 (5.7\%) and 14 out of 49 (28.6\%) men, respectively. Last known disease status for both alive and deceased patients is shown in Table 2. At the time of analysis, 74 men, 8 with CRPC, remained alive. Twenty-three men with metastatic PC had died; 19 of these deaths were considered to be because of PC.

Margin randomisation. Thirty-two patients in each group developed PSA failure (HR: 1.01, 95\% CI: 0.61-1.66; $P=0.92$ ). The median time to PSA failure from randomisation was 9.5 and 8 years in the 1.5- and 1-cm groups, respectively (Figure $2 \mathrm{~B}$ ). The 10 -year actuarial freedom from PSA failure rate was $47.4 \%$ (95\% CI:

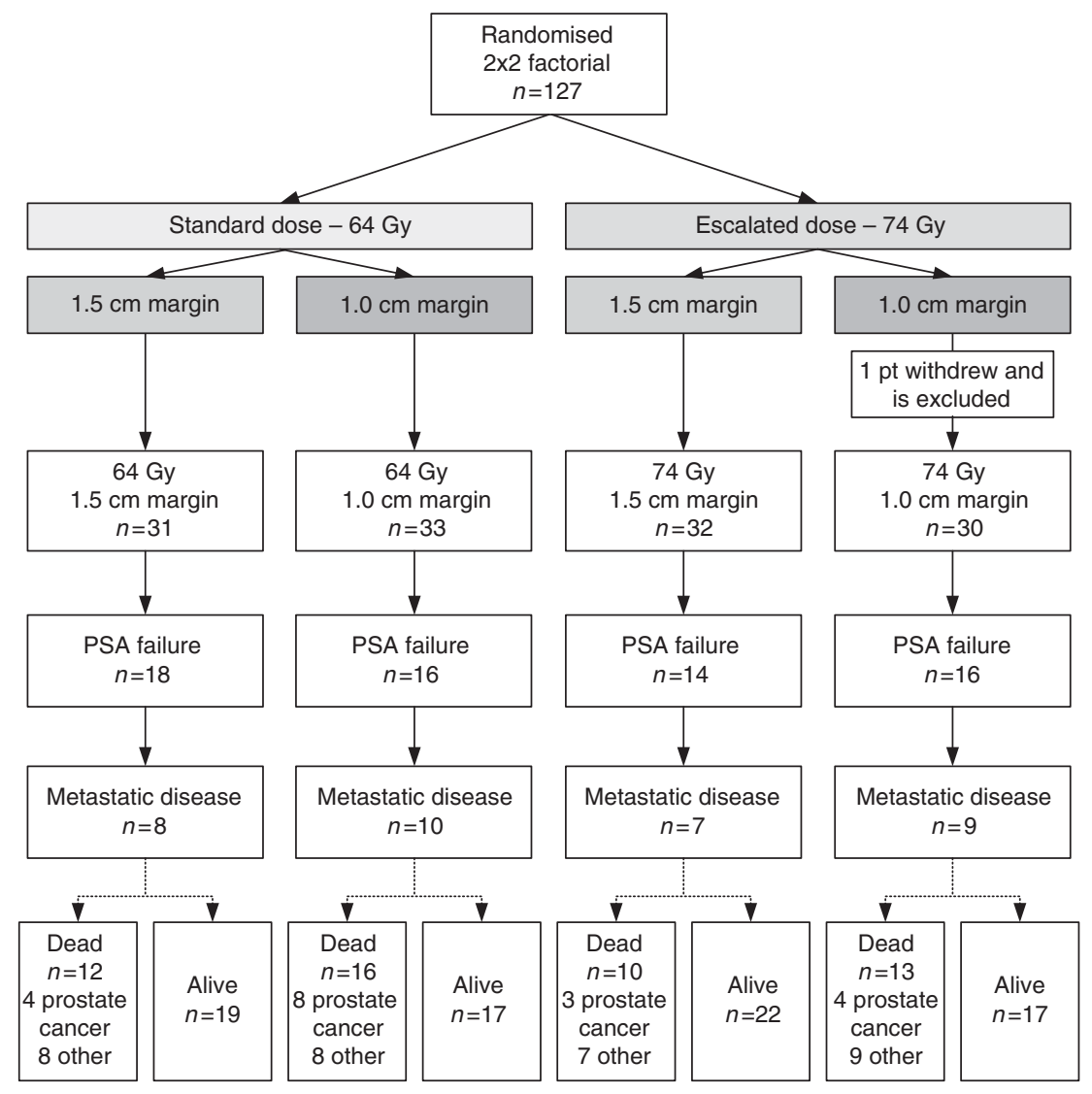

Figure 1. Patient flow.

Table 1. Number of events, hazard ratio and proportion event free at 10 years by randomised dose

$\mathbf{N}$

Proportion event free ${ }^{a}$ at 10 years $(95 \% \mathrm{Cl})$

\begin{tabular}{|c|c|c|c|c|c|c|c|c|c|}
\hline End point & $64 \mathrm{~Gy}(n=64)$ & 74 Gy $(n=62)$ & Hazar & tio $(95 \% \mathrm{Cl})$ & $\boldsymbol{P}$-value & & $4 \mathrm{~Gy}$ & & $4 \mathrm{~Gy}$ \\
\hline PSA failure & 34 & 30 & 0.77 & $(0.47-1.26)$ & 0.29 & 45.3 & $(32.1-57.7)$ & 49.3 & $(35.8-61.5)$ \\
\hline Hormones restart & 26 & 23 & 0.84 & $(0.48-1.48)$ & 0.56 & 64.8 & $(50.6-75.8)$ & 75.6 & $(62.1-84.8)$ \\
\hline Metastatic disease & 18 & 16 & 0.90 & $(0.46-1.77)$ & 0.78 & 81.3 & $(68.7-89.2)$ & 78.4 & $(65.0-87.1)$ \\
\hline CRPC & 17 & 14 & 0.81 & $(0.40-1.65)$ & 0.60 & 80.9 & (68.0-89.0) & 87.3 & $(75.1-93.8)$ \\
\hline Prostate cancer death & 12 & 7 & 0.59 & (0.23-1.49) & 0.29 & 88.0 & (76.4-94.1) & 94.8 & $(84.7-98.3)$ \\
\hline Death-any cause & 28 & 23 & 0.81 & $(0.47-1.40)$ & 0.49 & 73.4 & $(60.8-82.6)$ & 82.0 & $(69.8-89.6)$ \\
\hline
\end{tabular}

Abbreviations: $\mathrm{Cl}=$ confidence interval; $\mathrm{CRPC}=$ castrate-resistant prostate cancer; PSA= prostate-specific antigen.

${ }^{\text {a }}$ Kaplan-Meier point estimate. 

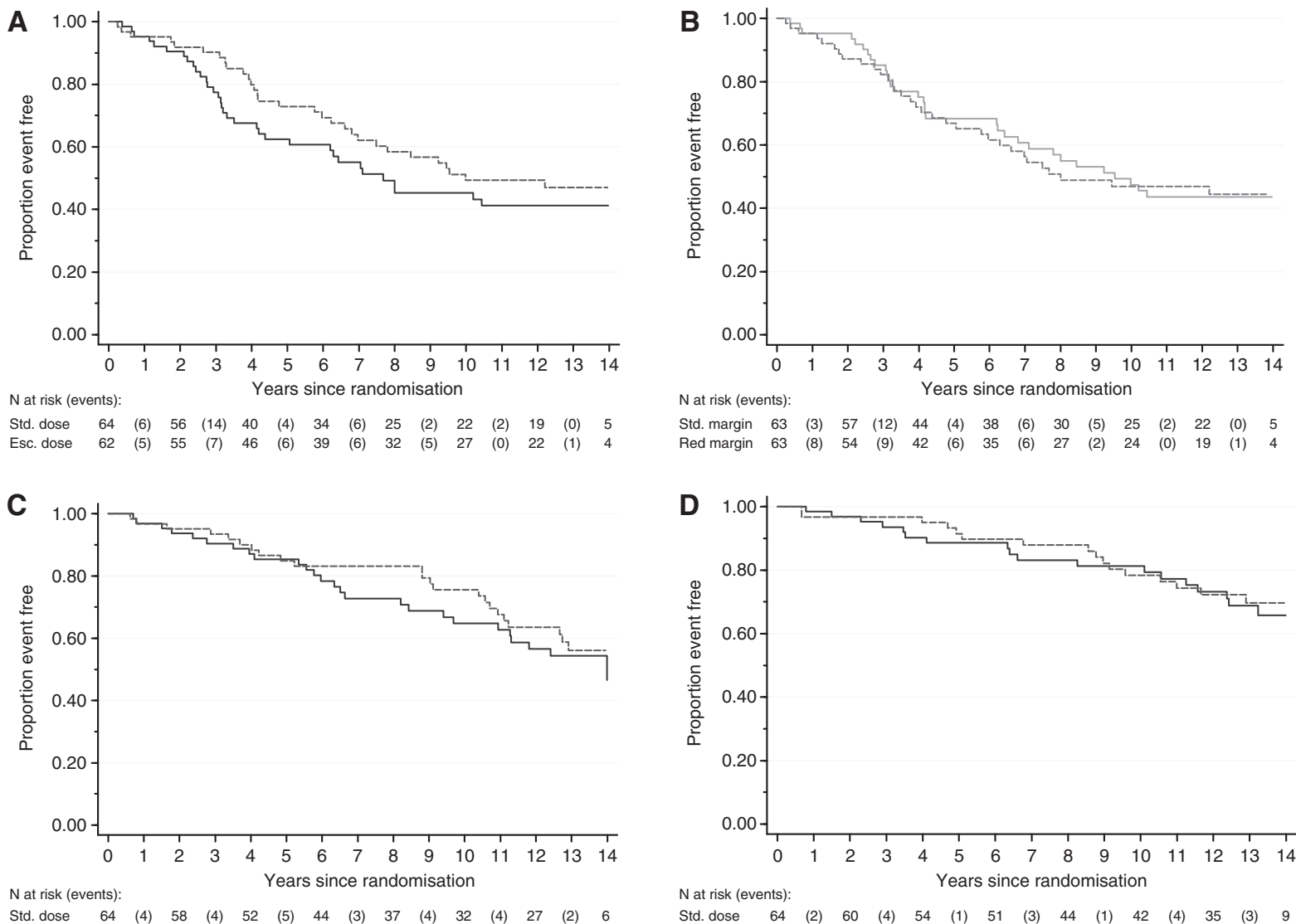

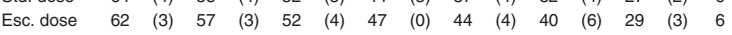

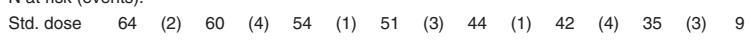

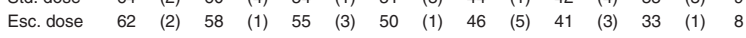
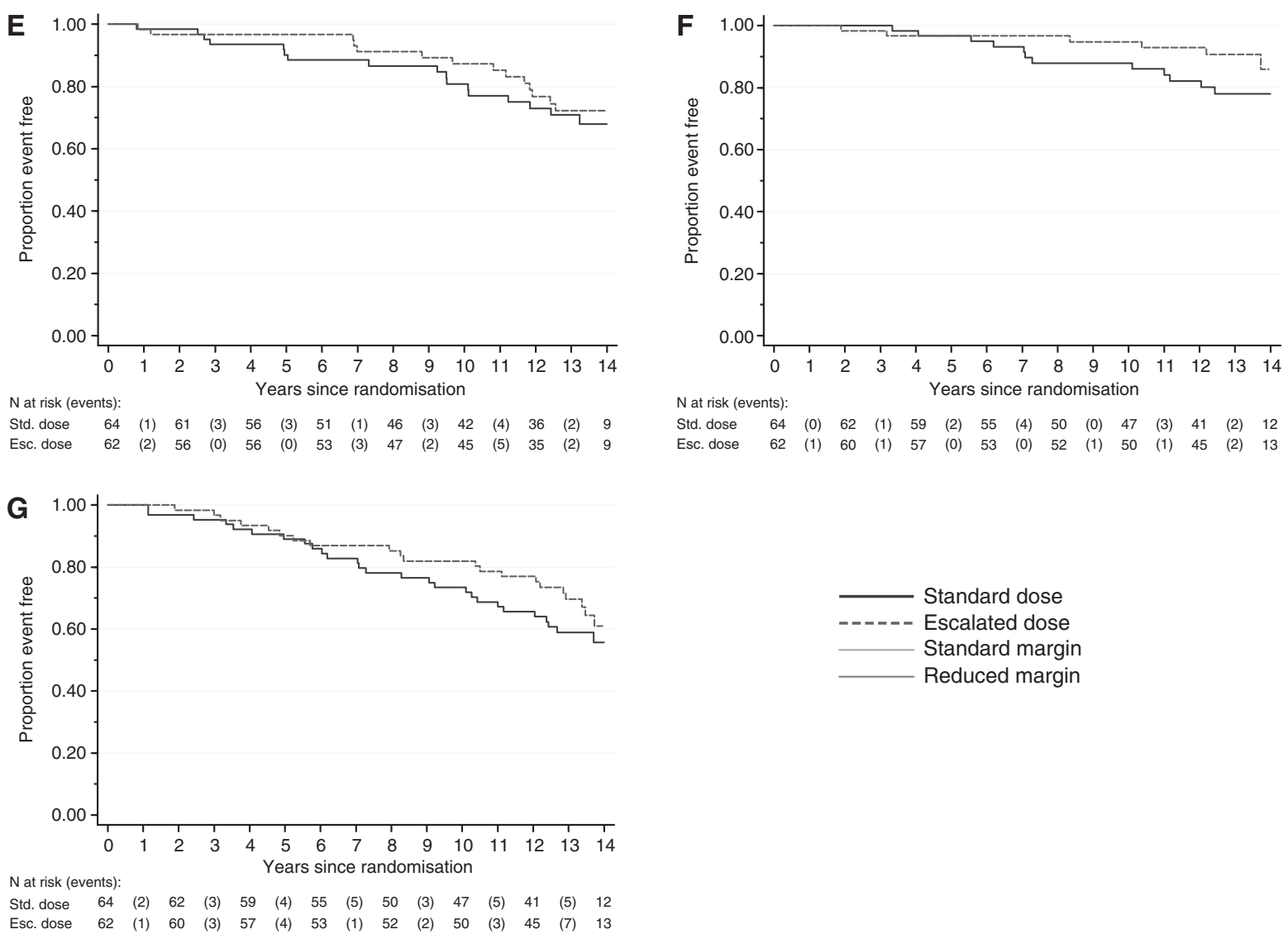

Figure 2. Kaplan-Meier plots. (A) Time to PSA failure (by dose), (B) time to PSA failure (by margin), (C) time to restart hormones (by dose), (D) time to metastatic disease (by dose), (E) time to CRPC (by dose), (F) PC-specific survival (by dose) and (G) OS (by dose). 


\begin{tabular}{|c|c|}
\hline Patient status & $\underset{(126)}{N}$ \\
\hline Alive & 74 \\
\hline No disease recurrence & 38 \\
\hline PSA/local failure only-no salvage hormonal treatment & 11 \\
\hline PSA/local failure only—with salvage hormonal treatment & 11 \\
\hline $\begin{array}{l}\text { Metastatic disease: nodal alone with salvage hormonal treatment; } \\
\text { PSA controlled }{ }^{\text {a }}\end{array}$ & 3 \\
\hline $\begin{array}{l}\text { Metastatic disease: extra nodal sites with salvage hormonal } \\
\text { treatment; PSA controlled }{ }^{\text {a }}\end{array}$ & 3 \\
\hline CRPC & 8 \\
\hline Dead-cause other than prostate cancer & 32 \\
\hline No disease recurrence/died of other causes & 23 \\
\hline PSA/local failure only-no salvage hormonal treatment & 3 \\
\hline $\begin{array}{l}\text { PSA/local failure only-with salvage hormonal treatment; PSA } \\
\text { controlled }^{\text {a }}\end{array}$ & 2 \\
\hline Metastatic disease: first-line hormonal therapy; PSA controlled ${ }^{a}$ & 2 \\
\hline CRPC; PSA controlled $^{\text {a }}$ & 2 \\
\hline Dead-prostate cancer & 19 \\
\hline CRPC; PSA uncontrolled ${ }^{\mathbf{b}}$ & 18 \\
\hline Prostate cancer on death certificate, but inadequate follow-up data & 1 \\
\hline Lost to follow-up & 1 \\
\hline \multicolumn{2}{|c|}{ 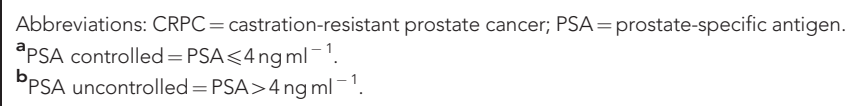 } \\
\hline
\end{tabular}

33.9-59.8\%) and 46.9\% (95\% CI: 33.6-59.2\%) for the 1.5- and $1-\mathrm{cm}$ groups, respectively. There were no significant differences between the groups for the other end points analysed (data not shown).

\section{DISCUSSION}

Radical conformal external beam radiotherapy, in conjunction with initial AS, is a standard form of management for localised PC. Considerable technical advances in radiation delivery have been achieved over the past two decades, including the introduction of $3 \mathrm{D}$ conformal techniques. This allowed the high-dose volume to be more closely matched to the tumour target, while reducing the radiation to dose-limiting normal tissues (Fuks and Horwich, 1993). This resulted in advantages including a potential reduction in radiation-related side effects, as well as the possibility of dose escalation to improve tumour control.

Dose escalation in PC is now standard practice in the United Kingdom (NICE, 2008) supported by results from several phase III trials including the evidence from our previous reports for this pilot study and the subsequent MRC RT01 trial. The studies have shown a consistent benefit in tumour control with dose escalation (Dearnaley et al, 2005, 2007; Al-Mamgani et al, 2008; Viani et al, 2009; Zietman et al, 2010; Kuban et al, 2011). The escalated 74-Gy dose with 6 months AS used in this pilot study, and the MRC RT01 trial was chosen as the control or comparator group in two subsequent UK national trials, CHHiP trial (CRUK/06/016), a randomised phase III multicentre trial of conventional or hypofractionated high-dose intensity-modulated radiotherapy (Khoo and Dearnaley, 2008; Dearnaley et al, 2012); and ProtectT trial (ISRCTN20141297), evaluating the effectiveness of treatment for clinically localised PC (Donovan et al, 2009; Lane et al, 2010). This pilot study and the larger MRC RT01 trial are the only doseescalation trials to use short-course neoadjuvant hormonal therapy in all patients. In the United Kingdom, this is standard practice (NICE, 2008) for the majority of men treated with intermediateand high-risk localised disease supported by results of phase III trials (Pilepich et al, 2001; D'Amico et al, 2004; Laverdiere et al, 2004; Bria et al, 2009; Shelley et al, 2009; Denham et al, 2011; Jones et al, 2011), showing an improvement in biochemical control and OS.

To our knowledge, this publication has the longest follow-up of any dose-escalation trial in PC reported to date, with only three other prospective studies reporting long-term data (Zietman et al, 2010; Dearnaley et al, 2011; Kuban et al, 2011). A strength of the study is the long- and near-complete follow-up (2\% patients lost to follow-up). This will be harder to achieve in larger UK trials with long follow-up, in which many patients will have developed co-morbidities that restrict their ability to attend the outpatient clinic, have moved away or died of unknown causes. Other strengths include the consistent treatment, and the mature data concerning metastases development, and survival including detailed review of causes of death. Limitations include the small number of patients in a single centre pilot study and the radiotherapy techniques employed, which although 'state-of-the art' at the time, have now been superseded by intensity-modulated and image-guided methods.

In view of the small size of this study, none of the results reached statistical significance and they should therefore be regarded as hypothesis generating. Retrospective power calculations suggest that with 127 patients and an observed 63\% PSA control rate in the 64 -Gy group, there is $80 \%$ power to detect a $19 \%$ improvement in the 5-year PSA control rate in the 74-Gy group ( $5 \%$ one-sided alpha). This would have been an unexpectedly large difference; nevertheless, there is a suggestion that the escalated dose (74 Gy) may improve PSA control (HR: 0.77) with a 2.3-year increase in the median time to PSA failure, reduce the development of CRPC (HR: 0.81) and improve PC-specific survival (HR: 0.59) and OS (HR: 0.81). This is of interest as no phase III trial has yet demonstrated an improvement in the overall or cause-specific survival with dose escalation. It may be that prolonged patient follow-up will be required for such benefits to become apparent; this has resource implications for trial conduct and highlights the potential value of high-quality electronically linked routinely collected outcome data.

This study is the only randomised trial in PC to address the issue of radiation 'safety margin' with $3 \mathrm{D}$ conformal techniques after initial hormone therapy. A 'safety margin' is necessary to allow for microscopic spread, prostate movement, for example, due to rectal distension, outlining uncertainties and set-up errors. Our experience suggested at the time suggested that a $1.0-\mathrm{cm}$ margin was adequate to incorporate these uncertainties (Huddart et al, 1996) but we additionally wished to find out whether it was appropriate to treat the initial prostate volume before hormone treatment or the target volume after hormone cytoreduction, which we had shown on average corresponded to a $0.5-\mathrm{cm}$ reduction in target radius (Shearer et al, 1992). We previously reported a statistically significant reduction in both acute and late side effects and no evidence for a reduction in PSA control using a $1.0-\mathrm{cm}$ margin rather than a $1.5-\mathrm{cm}$ margin to the post-hormone treatment target volume (Dearnaley et al, 2005). The updated results confirm there is no detrimental effect of using the smaller margin on disease control.

The PSA failure event curve (Figure 2A) appears to separate out after $\sim 2.5$ years follow-up in favour of the 74-Gy arm. It was perhaps surprising that the delay in PSA failure did not appear to translate into a delay in starting salvage hormonal therapy. This 
may just be the 'play of chance' and because of the small number of patients in this study. However, it may reflect the balance of local and distant failures between the randomised groups with relatively more indolent (and local) failures occurring in the 64-Gy group.

To date, all prospective phase III dose-escalation trials have consistently shown an improvement in PSA control with higher radiation doses (Dearnaley et al, 2005, 2007; Al-Mamgani et al, 2008; Viani et al, 2009; Zietman et al, 2010; Kuban et al, 2011); however, none of them, including the three trials with long-term follow-up (median 9-10 years; Zietman et al, 2010; Dearnaley et al, 2011; Kuban et al, 2011), have demonstrated statistically significant improvements in PC-specific or OS. This emphasises the necessity for long-term follow-up. However, a large retrospective analysis from the Radiotherapy and Oncology Group found men with highgrade cancers who received higher radiation doses $(\geqslant 66 \mathrm{~Gy} v \mathrm{~s}$ $<66$ Gy) had a $20 \%$ lower risk of death from PC and a $27 \%$ reduction in overall mortality (Valicenti et al, 2000). Similarly, a recent retrospective review (Kim et al, 2012) of 2675 patients treated at the MD Anderson Hospital confirmed the favourable outcome of localised PC after radical radiotherapy particularly for men with lower- or intermediate-risk disease, with $\leqslant 5 \%$ of men dying because of PC. A benefit for dose escalation $(\geqslant 72 \mathrm{~Gy}$ compared with $<72 \mathrm{~Gy}$ ) was suggested after $\geqslant 10$-year follow-up in high-risk patients, and particularly good outcome was noted if additional androgen deprivation therapy was used. In our present series, the considerable majority (16 out of 19) PC-related deaths occurred in men with high-risk disease, which mirrors the experience in the MD Anderson dose-escalation trial where 9 out of 10 PC-related deaths occurred in patients with high-risk disease (Kuban et al, 2011).

The results of this pilot study suggest that the improvement in PSA control persists long-term after dose-escalated radiotherapy. Additional follow-up from the substantive phase III trials is needed to confirm the trend for improvement in PC-specific and OS. A $1.0-\mathrm{cm}$ margin to create the PTV appears adequate after 6 months initial hormone treatment but further improvements in radiotherapy technique need to be evaluated and implemented to minimise treatment-related side effects.

We intend that the results of this pilot study are combined in meta-analysis with the other phase III randomised trials when the individual studies have reported more complete long-term follow-up.

\section{ACKNOWLEDGEMENTS}

This work was undertaken in the Royal Marsden NHS Foundation Trust, which received a proportion of its funding from the NHS Executive. We acknowledge NHS funding to the NIHR Biomedical Research Centre. This work was supported by the Institute of Cancer Research (ICR), and Cancer Research UK (CRUK) Grant Number C46/A3970 to the ICR Section of Radiotherapy and C1491/A9895 to the ICR Clinical Trials and Statistics Unit.

\section{DISCLAIMER}

The views expressed in this publication are those of the authors and not necessarily those of the NHS Executive.

\section{REFERENCES}

Al-Mamgani A, van Putten WL, Heemsbergen WD, van Leenders GJ, Slot A, Dielwart MF, Incrocci L, Lebesque JV (2008) Update of Dutch multicenter dose-escalation trial of radiotherapy for localized prostate cancer. Int $J$ Radiat Oncol Biol Phys 72(4): 980-988.
Bria E, Cuppone F, Giannarelli D, Milella M, Ruggeri EM, Sperduti I, Pinnaro P, Terzoli E, Cognetti F, Carlini P (2009) Does hormone treatment added to radiotherapy improve outcome in locally advanced prostate cancer?: meta-analysis of randomized trials. Cancer 115(15): 3446-3456.

CRUK (2009) CRUK CancerStats Key Facts: prostate cancer. In: http://www.info.cancerresearchuk.org/cancerstats/types/prostate/?script=true.

D’Amico AV, Manola J, Loffredo M, Renshaw AA, DellaCroce A, Kantoff PW (2004) 6-month androgen suppression plus radiation therapy $v s$ radiation therapy alone for patients with clinically localized prostate cancer: a randomized controlled trial. JAMA 292(7): 821-827.

Dearnaley D (2000) Combined modality treatment with radiotherapy and hormonal treatment in localised prostate cancer. In New Perspectives in Prostate Cancer, Belldegrun A, Kirby R, Newling D (eds) pp 169-180. Isis Medical Media Ltd: Oxford, UK.

Dearnaley D, Syndikus I, Sumo G, Bidmead M, Bloomfield D, Clark C, Gao A, Hassan S, Horwich A, Huddart R, Khoo V, Kirkbride P, Mayles H, Mayles P, Naismith O, Parker C, Patterson H, Russell M, Scrase C, South C, Staffurth J, Hall E (2012) Conventional versus hypofractionated high-dose intensitymodulated radiotherapy for prostate cancer: preliminary safety results from the CHHiP randomised controlled trial. Lancet Oncol 13(1): 43-54.

Dearnaley DP, Hall E, Lawrence D, Huddart RA, Eeles R, Nutting CM, Gadd J, Warrington A, Bidmead M, Horwich A (2005) Phase III pilot study of dose escalation using conformal radiotherapy in prostate cancer: PSA control and side effects. Br J Cancer 92(3): 488-498.

Dearnaley DP, Jovic G, Syndikus I, Graham JD, Aird EG, Khoo V, Cowan R, Sydes MR. on behalf of RT01 Investigators (2011) Escalated-dose conformal radiotherapy for localised prostate cancer: long term overall survival results from the MRC RT01 randomised controlled trial. Eur J Cancer 47(Suppl 2): 11-12.

Dearnaley DP, Sydes MR, Graham JD, Aird EG, Bottomley D, Cowan RA, Huddart RA, Jose CC, Matthews JH, Millar J, Moore AR, Morgan RC, Russell JM, Scrase CD, Stephens RJ, Syndikus I, Parmar MK (2007) Escalated-dose versus standard-dose conformal radiotherapy in prostate cancer: first results from the MRC RT01 randomised controlled trial. Lancet Oncol 8(6): 475-487.

Denham JW, Steigler A, Lamb DS, Joseph D, Turner S, Matthews J, Atkinson C, North J, Christie D, Spry NA, Tai KH, Wynne C, D’Este C (2011) Short-term neoadjuvant androgen deprivation and radiotherapy for locally advanced prostate cancer: 10-year data from the TROG 96.01 randomised trial. Lancet Oncol 12(5): 451-459.

Donovan JL, Lane JA, Peters TJ, Brindle L, Salter E, Gillatt D, Powell P, Bollina P, Neal DE, Hamdy FC (2009) Development of a complex intervention improved randomization and informed consent in a randomized controlled trial. J Clin Epidemiol 62(1): 29-36.

Fuks Z, Horwich A (1993) Clinical and technical aspects of conformal therapy. Radiother Oncol 29(2): 219-220.

Huddart RA, Nahum A, Neal A, McLean M, Dearnaley DP, Law M, Dyer J, Tait D (1996) Accuracy of pelvic radiotherapy: prospective analysis of 90 patients in a randomised trial of blocked versus standard radiotherapy. Radiother Oncol 39(1): 19-29.

Jones CU, Hunt D, McGowan DG, Amin MB, Chetner MP, Bruner DW, Leibenhaut MH, Husain SM, Rotman M, Souhami L, Sandler HM, Shipley WU (2011) Radiotherapy and short-term androgen deprivation for localized prostate cancer. N Engl J Med 365(2): 107-118.

Khoo VS, Bedford JL, Webb S, Dearnaley DP (2000) An evaluation of threefield coplanar plans for conformal radiotherapy of prostate cancer. Radiother Oncol 55(1): 31-40.

Khoo VS, Dearnaley DP (2008) Question of dose, fractionation and technique: ingredients for testing hypofractionation in prostate cancer: the CHHiP trial. Clin Oncol (R Coll Radiol) 20(1): 12-14.

Kim MM, Hoffman KE, Levy LB, Frank SJ, Pugh TJ, Choi S, Nguyen QN, McGuire SE, Lee AK, Kuban DA (2012) Prostate cancer-specific mortality after definitive radiation therapy: who dies of disease? Eur J Cancer 48(11): 1664-1671.

Kuban DA, Levy LB, Cheung MR, Lee AK, Choi S, Frank S, Pollack A (2011) Long-term failure patterns and survival in a randomized dose-escalation trial for prostate cancer. Who dies of disease? Int J Radiat Oncol Biol Phys 79(5): 1310-1317.

Lane JA, Hamdy FC, Martin RM, Turner EL, Neal DE, Donovan JL (2010) Latest results from the UK trials evaluating prostate cancer screening and treatment: the CAP and ProtecT studies. Eur J Cancer 46(17): 3095-3101. 
Laverdiere J, Nabid A, De Bedoya LD, Ebacher A, Fortin A, Wang CS, Harel F (2004) The efficacy and sequencing of a short course of androgen suppression on freedom from biochemical failure when administered with radiation therapy for T2-T3 prostate cancer. J Urol 171(3): 1137-1140.

NICE (2008) (NCC-C) NICE Clinical Guideline: Prostate cancer: diagnosis and treatment (CG58). In: http://www.guidance.nice.org.uk/CG58.

Pickett B, Roach M, Horine P, Verhey L, Phillips TL (1994) Optimization of the oblique angles in the treatment of prostate cancer during six-field conformal radiotherapy. Medi Dosimetry 19: 237-254.

Pilepich MV, Winter K, John MJ, Mesic JB, Sause W, Rubin P, Lawton C, Machtay M, Grignon D (2001) Phase III radiation therapy oncology group (RTOG) trial 86-10 of androgen deprivation adjuvant to definitive radiotherapy in locally advanced carcinoma of the prostate. Int J Radiat Oncol Biol Phys 50(5): 1243-1252.

Roach III M (1993) Re: The use of prostate specific antigen, clinical stage and Gleason score to predict pathological stage in men with localized prostate cancer. J-Urol 150(6): 1923-1924.

Shearer RJ, Davies JH, Gelister JS, Dearnaley DP (1992) Hormonal cytoreduction and radiotherapy for carcinoma of the prostate. Br J Urol 69(5): 521-524.

Shelley MD, Kumar S, Coles B, Wilt T, Staffurth J, Mason MD (2009) Adjuvant hormone therapy for localised and locally advanced prostate carcinoma: a systematic review and meta-analysis of randomised trials. Cancer Treat Rev 35(7): 540-546.

Valicenti R, Lu J, Pilepich M, Asbell S, Grignon D (2000) Survival advantage from higher-dose radiation therapy for clinically localized prostate cancer treated on the Radiation Therapy Oncology Group trials. J Clin Oncol 18(14): 2740-2746.

Viani GA, Stefano EJ, Afonso SL (2009) Higher-than-conventional radiation doses in localized prostate cancer treatment: a meta-analysis of randomized, controlled trials. Int J Radiat Oncol Biol Phys 74(5): $1405-1418$.

Zietman AL, Bae K, Slater JD, Shipley WU, Efstathiou JA, Coen JJ, Bush DA, Lunt M, Spiegel DY, Skowronski R, Jabola BR, Rossi CJ (2010) Randomized trial comparing conventional-dose with high-dose conformal radiation therapy in early-stage adenocarcinoma of the prostate: long-term results from proton radiation oncology group/american college of radiology 95-09. J Clin Oncol 28(7): 1106-1111.

This work is published under the standard license to publish agreement. After 12 months the work will become freely available and the license terms will switch to a Creative Commons AttributionNonCommercial-Share Alike 3.0 Unported License. 